\title{
Reflexões Cotidianas Em Tempos Pandêmicos: Sobre educação, democracias e desigualdades socias, que lições aprenderemos com a pandemia?
}

\author{
Carla Aparecida Costa \\ Universidade Federal do Estado do Rio de Janeiro - UniRio/RJ, Brasil \\ E-mail: cah.costa84@edu.unirio.br
}

\section{Resumo}

O presente ensaio visa refletir sobre as formas de ensino remoto e os impactos ocasionados pela Covid-19 durante o primeiro período letivo de 2020. Pretende-se propor um debate acerca das condições dadas aos alunos e professores para o cumprimento do calendário acadêmico. Assim como diversos setores da nossa sociedade, o sistema educacional brasileiro se viu obrigado a se reinventar diante do cenário atual da pandemia que afeta o mundo todo. Para o desenvolvimento da nossa reflexão, apresentamos as especificidades de trêsgrupos de alunos, de diferentes instituições, com perfis socioeconômicos diversificados e com acessibilidades virtuais limitadas. Pretende-se mostrar ao longo desse ensaio as desigualdades sociais que a pandemia trouxe para superfície e como ela atinge diretamente alunos e professores. O primeiro grupo é formado por alunos do curso de Moda e Modelagem do Vestuário, do Instituto Federal de Goiás (IFG), onde nossa observação se deu a partir das aulas práticas de elaboração de peças históricas do vestuário. No segundo grupo, estão alunos da Faculdade de Dança Angel Vianna RJ (EFAV) a partir das aulas de visualidades da cena eo processo criativo para figurino de dança. $E$, no terceiro grupo, são alunos do laboratório de criação (figurino de cena) que ocorreu na Universidade Federal do Estado do Rio de Janeiro (UniRio). Em todas as instituições, as observações surgem do olhar $\mathrm{e}$ da prática docente entre abril e dezembro de 2020.

\section{Palavras-chave}

Ensino remoto; Aprendizado; Desigualdade social; Inclusão digital.
This essay aims to reflect on the forms of remote education and the impacts caused by Covid-19 during the 2020.1 academic period. It is intended to propose a debate about the conditions given to students and teachers to comply with the academic calendar. Like several sectors of our society, the Brazilian educational system was forced to reinvent itself in the face of the current scenario of the pandemic that affects the whole world. For the development of our reflection, we present the specificities of three student groups, from different institutions, with diverse socio-economic profiles, and with limited virtual accessibility. It is intended to show throughout this essay the social inequalities that the pandemic brought to the surface and how it directly affects students and teachers. The first group are students from the Fashion and Clothing Modeling course at the Federal Institute of Goiás (IFG), where our observation took place from the practical classes in the elaboration of historical garments. In the second group are students from the Angel Vianna Dance College - RJ (EFAV) from the scene visualization classes and the creative process for dance costumes. And in the third group are students from the creative laboratory (stage costumes) that took place at the Federal University of the State of Rio de Janeiro (UniRio). In all institutions, observations emerge from the perspective and teaching practice between April and December 2020.
Remote education; Learning; Social inequality; Digital inclusion. 


\section{Democracia e desigualdade} no acesso à educação

Esse ensaio surge no momento que a sociedade brasileira enfrenta um dos seus maiores desafios: a pandemia do novo coronavírus (Covid-19). Um vírus que se espalhou pelos cinco continentes e que pôs a população mundial em estado de alerta. Já se passaram meses e ainda estamos tentando calcular quais serão os impactos dessa doença na sociedade, mas não sabemos mensurar seus efeitos e as sequelas que ficarão na história. Já os impasses e a má atuação do Governo Federal frente à covid-19 provocam instabilidades em diversas áreas da vida social. Não ter segurança ou qualquer perspectiva diante da crise que atingiu a saúde brasileira é um problema gravíssimo e parte dele é abordado nesse ensaio. Atentamos aqui para os impactos da pandemia sobre a educação e os agravantes da exclusão social e digital.

As aulas presenciais estão suspensas desde meados de março de 2020. O conselho de infectologistas é que a retomada total das atividades presenciais só aconteça após a vacinação da população. Muitos pesquisadores já têm apontado que um retorno completo à normalidade em todos os países só será possível com o controle da pandemia. Mas até que essa realidade seja alcançada na sociedade brasileira, temos outros problemas que carecem de cuidados urgentes. As dificuldades ocasionadas na educação precisam ser observadas, revistas e levadas para o primeiro plano de discussão, independentemente da situação em que estamos vivendo.

Os desafios científicos e tecnológicos colocados pelo vírus vão, contudo, muito além da vacina. Não precisamos esperar por ela, ou mesmo pelo fim da pandemia, para pensar estratégias para a educação. Nesse sentido, neste ensaio abordaremos a educação na era digital, bem como a exclusão/ inclusão tecnológica de jovens e adultos que não tiveram oportunidade de acessar ferramentas que hoje são obrigatórias em sala de aula. Segundo Pedro Demo (2005, p.37), professor na Universidade de Brasília (UnB), a exclusão digital "é problema agudo de países atrasados, mas acomete também vastas camadas em países avançados, porque muitos adultos/idosos não se propõem mais inserir-se na sociedade digital com autonomia". Esse ponto da abordagem de Demo nos interessa justamente porque alguns dos nossos grupos de alunos são jovens e adultos da rede pública que estão matriculados na modalidade de Ensino de Jovens e Adultos (EJA).

Além disso, refletimos sobre a dificuldade e a falta de preparo do corpo docente diante do ensino remoto. O perfil dos alunos analisados em nossa abordagem contribui para evidenciar o que Demo apontou,em 2005, em seus estudos: a desigualdade social, o analfabetismo digital e a falta de instrução do corpo docente. Segundo ele:

[...] não se pode imaginar que, de repente, pudéssemos saltar por cima do atraso tecnológico nacional ou por cima da necessidade de infraestruturas adequadas. Em muitos interiores, a infraestrutura é ainda muito precária para abrigar a nova mídia em condições mínimas. Segundo, a inclusão digital na escola depende, em grande medida, da qualidade docente, no sentido de que os professores precisam enfronhar-se definitivamente nesta seara, o que, em geral, a pedagogia e a licenciatura não fazem, sem falar nas condições socioeconômicas adversas. (DEMO, 2005, p.37).

Esses são os agravantes de uma sociedade cujos governantes não se preocuparam com a inclusão, com a equidade e com a igualdade em termos de acessibilidade digital. Todas essas questões necessitam de um esforço muito grande e ágil, para que possam dar respostas a tempo de minimizar os efeitos da crise da pandemia sobre a educação.

Nossa análise também foi conduzida por perguntas essenciais para essa reflexão, tais como: (a) como ministrar atividades práticas para os alunos da modalidade EJA garantindo a qualidade do ensino? (b) quais são as condições de aprendizado desses alunos nesse momento de pandemia? (c) que parâmetros guiam a aplicabilidade do ensino remoto para os alunos? (d) como garantir o aprendizado e a qualidade do ensino, nesse formato, para os alunos que nunca tiveram acesso às redes virtuais? Essas ques- 
tões foram levantadas desde o início da pandemia, momento em que tivemos as aulas suspensas e quando ficou claro que os semestres seguintes estariam sujeitos aos novos desafios das plataformas digitais.

Uma das maiores preocupações era manter a qualidade e o conteúdo das aulas presenciaissem que houvesse prejuízos na formação do aluno, principalmente no que diz respeito às disciplinas práticas. Salientamos que o perfil do alunado EJA é diverso. Boa parte dos alunos esteve fora da sala de aula por muito tempo. Muitos deles possuem empregos e, mesmo durante a pandemia, mantiveram suas rotinas de trabalho. Outros perderam seus empregos e enfrentaram problemas diversos: financeiros, de saúde, baixa motivação para os estudos, problemas de conexão e, por fim, a dificuldade de se adequar aos novos métodos.

O curso de Modelagem do Vestuário é um curso teórico/prático com ênfase no desenvolvimento de produtos para o vestuário, focado no fazer diário do aluno que tem aulas de corte/costura e desenvolvimento de produto. Um dos agravantes do ensino remoto é a estrutura física que o aluno dispõe no instituto, mas não em casa. Ao ministrar um conteúdo prático em sala de aula e perceber a dificuldade no desenvolvimento do aluno, de imediato o professor orienta e busca a solução para o problema. Isso não ocorre com o mesmo dinamismo no ensino remoto. As aulas teóricas fluem de modo mais natural, menos afetadas por dificuldades de comunicação ou pela falta de atenção do aluno. Contudo,nas aulas de modelagem tridimensional do vestuário, por exemplo, é impossível garantir a qualidade do aprendizado e afirmar que o aluno desenvolveu, com exatidão, o conteúdo proposto.

Ao traçar as bases planas de modelagens do vestuário, muitos alunos cometem erros no processo do desenvolvimento que não são percebidos pelo professor, pois os alunos não se sentem à vontade para ligar a câmera do dispositivo e fazer as devidas correções nas tarefas. Assim, a dinâmica de acompanhamento das atividades práticas tem obstáculos constantes. Se os alunos não buscam ajuda do professor ouse nós não percebemos a dificuldade do aluno em desenvolver a atividade, a qualidade do ensino é falha.

O primeiro semestre do ano letivo de 2020 foi, sem dúvida alguma, um ano atípico tanto para professores quanto para alunos. Podemos afirmar também que foi o ano em que as diferenças entre classes sociais impactaram diretamente na relação entre ensino e aprendizado e na relação professor/ aluno. O Ministério da Educação (MEC), ao homologar o conjunto de diretrizes do Conselho Nacional de Educação (CNE), ignora muitas questões sociais - o fato de que parte significativa da população brasileira não tem acesso às tecnologias necessárias, por exemplo - e põe em risco o aprendizado e a saúde física e mental dos discentes e docentes.

De acordo com o MEC, o documento aprovado pelo $C N E$, no final de abril, traz orientações para as instituições de ensino em relação às iniciativas que devem ser tomadas durante o período da pandemia. No documento que pode ser lido na integra no site do Portal do MEC (2020), nota-se a preocupação em não colocar a perder o calendário acadêmico, mas também que ele é insuficiente quanto a orientações que priorizem a qualidade do ensino.

Antes de apontar os entraves que ocorreram no semestre letivo de ensino remoto, queremos fazer uma breve abordagem sobre democratização de ensino, porque entendemos que é a partir daí que nossa análise ganha sentido. Mas o que tem a ver democracia com a pandemia e o ensino remoto? Por Lei, no Estado Democrático de Direito, as leis são criadas pelo povo e para o povo e, em linhas gerais, a democracia é o exercício do poder político por parte do povo, respeitando assim a dignidade da pessoa humana.

A atual pandemia põe em xeque a democracia do país ao evidenciar quem está e quem não está sob a proteção do Estado Brasileiro. Boaventura de Sousa Santos, em sua abordagem sobre a "Pedagogia do Vírus", inicia o capítulo dizendo: "Existe um debate nas ciências sociais sobre se a verdade e a qualidade das instituições de uma dada sociedade se conhecem melhor em situações de normalidade, de funcionamento corrente, ou em situações excepcionais, de crise." (SANTOS, 2020, p. 5). 
Sobre democracia o autor salienta:

A democracia representativa (DR) é o regime político no qual os cidadãos (inicialmente uma pequena porcentagem da população) concentram seu poder democrático na eleição dos decisores políticos. Uma vez eleitos, estes passam a ser os titulares do poder democrático que exercem com mais ou menos autonomia em relação aos cidadãos. Essa autonomia dos representantes é algo paradoxal. Se, por um lado, é um requisito para que a democracia funcione, por outro, é um fator de tensão entre representantes e representados, a ponto de em algumas situações a maioria dos representados não se reconhecer nos representantes, não se sentir representada por estes (a patologia da representação). (SANTOS, 2016, p.85).

É acreditando na ação dos representantes que a população escolhe seus candidatos. Acredita-se também que essas ações estão voltadas, principalmente, para as populações das classes sociais mais vulneráveis. Parte dessa sociedade vulnerável está atualmente matriculada em algum nível de ensino e foi a mais afetada durante o ensino remoto.

Boaventura apresenta que a distância entre representantes e representados transforma-se, pouco a pouco, na patologia da participação e acrescenta que "os cidadãos se convencem de que seu voto não muda as coisas e, por isso, deixam de fazer o esforço (por vezes, considerável) de votar; assim, surge o abstencionismo" (SANTOS, 2016, p. 85). De fato, o abandono dos representados por seus representantes têm tomado proporções assustadoras. Os dados alarmantes da saúde pública, bem como a forma de elaboração dos planos do Ministério da Educação no período da pandemia, deixam claro como as populações periféricas do Brasil estão às margens das agendas políticas.

No âmbito do que entendemos por democracia está a garantia dos direitos humanos e as políticas públicas que visam dar à população os chamados bens de direitos básicos, tais como moradia, segurança, saúde, emprego e educação. Na educação, por exemplo, a democracia reside em tornar acessível o ingresso aos níveis básicos de educa- ção e dar condições de permanência ao alunado.

Em síntese, democratizar o ensino exige resolver questões básicas de equidade, igualdade e qualidade. São esses os fatores que nos fizeram refletir sobre as formas de ensino remoto que têm ocorrido durante a pandemia que atingiu tão drasticamente o país. Diante disso, questionamos que democracia existe no acesso à educação, quando um plano emergencial de ensino remoto não leva em conta a carência básica do aluno que sempre esteve excluído do sistema digital. A quem serve esta democracia? Dar um dispositivo eletrônico para alunos de baixa renda não parece ser suficiente para democratizar o ensino. O esgotamento da saúde mental dos professores, que recebem alunos em condições frágeis de aprendizado, também não foi levado em conta. Da mesma forma, não houve preocupação em garantir a qualidade do ensino em uma situação na qual o professor sequer sabe o que está acontecendo do outro lado da câmera.

A pandemia escancarou uma crise que já existia no sistema educacional brasileiro e apresenta complicações sérias tanto para quem ministra aulas quanto para quem está em processo de formação. A partir dos questionamentos expostos e da análise do perfil de alguns alunos percebemos a fragilidade do sistema.

\section{Relatos da experiência docente durante a pandemia}

Nossa primeira reflexão aborda as ações tomadas pela Faculdade de Dança Angel Vianna. Vale salientar que nossa análise não é uma crítica às instituições, mas sim ao sistema que diz democratizar a educação. Assim que houve a paralisação inicial por conta da pandemia, a EFAV buscou recursos para a retomada das aulas, e isso aconteceu em tempo recorde. Trata-se de uma instituição de porte pequeno se comparado aos Institutos Federais e, portanto, os problemas também são em menor proporção. Mas não é sobre a eficiência das instituições em resolver seus problemas que voltamos nosso olhar, é sobre o ensino, a qualidade e a condição dos alunos em operar os sistemas digitais que agora são exigidos. 
O primeiro contato com os alunos da EFAV se deu em abril de 2020, um mês após a paralisação. Assim como eu, os alunos estavam em um novo ambiente e tudo era meio confuso. Foi o primeiro semestre de ensino remoto e a primeira vez que eu entro numa plataforma digital para ministrar. Foi ali que percebi que não veria o rosto dos alunos a menos que eles se sentissem à vontade para ligar a câmera do dispositivo. O diálogo inicial foi difícil, mas por se tratar de uma turma jovem, acostumada ao meio digital e às redes, não demorou muito para que a fluidez nas aulas acontecesse.

Apesar disso,levar as aulas práticas de figurino para o ambiente virtual era algo pouco provável, mesmo para os alunos que tinham espaços e condições de adaptações, como foi o caso de alguns alunos da EFAV. Esse é um aspecto consideravelmente relevante nas aulas práticas. As adaptações por parte de discentes e docentes exigem um tempo que nem sempre temos, exigem habilidades especificas que em muitos não foram desenvolvidas. Mas, na medida do possível, os alunos conseguiram se adaptar e assimilar grande parte do conteúdo ministrado. Outro fato relevante para esse grupo é que os alunos raramente faltavam às aulas.

O Instituto Federal de Goiás, por sua vez, trouxe para a superfície os problemas que evidenciam a inexistência da democratização, da equidade e da qualidade de ensino. No IFG meu contato se deu a partir de setembro, mesmo mês em que os alunos retomaram as aulas (remotas) do primeiro semestre letivo. A aula remota era novidade para eles. Eu já havia vivenciado e a insegurança dessa vez era menor. O perfil desses alunos, por sua vez, era bem diferente do perfil dos alunos da EFAV e também diverso dentro da própria turma.

No IFG as aulas foram ministradas para o Ensino Médio - Educação para Jovens e Adultos (EJA). A EJA é um programa do governo que visa oferecer o Ensino Fundamental e Médio para pessoas que pararam de estudar por um longo tempo ou que não tiveram oportunidade. $\mathrm{O}$ aluno mais novo dessa turma tinha em torno de vinte anos, enquanto o mais velho, cerca de sessenta. Alguns alunos estavam afastados da sala de aula há mais de quarenta anos.

Como equalizar o ensino remoto diante dessa situação? Nossas escolas não foram preparadas para essas adversidades e, na EJA, os alunos geralmente são trabalhadores/as, empregados/as ou desempregados/as, que não tiveram acesso à escola. Um caso que nos serve de exemplo para nossa reflexão, uma aluna do segundo ano não assistia às aulas porque não sabia entrar na plataforma do GoogleMeet. Ela só conseguiu acessar no último mês do semestre letivo. No entanto, ela buscou formas de colocar todas as atividades em dia, fez os trabaIhos que foram propostos para a turma e alcançou média para aprovação. Outra aluna, que sempre esteve presente nas aulas, não conseguia acompanhar com atenção o conteúdo, pois tinha problemas pessoais que se agravaram com a pandemia. Ela não tinha nota suficiente para passar, mas assistia às aulas, fazia as atividades e se esforçava. Algo travava o processo de aprendizagem dela, algo que nem sempre percebemos e esse caso, por exemplo, só foi exposto no colegiado na última semana.

Esse é apenas um dos casos em que tivemos muita dificuldade para resolver o problema. Entre a aluna que não acessava as aulas remotamente e a aluna que estava sempre presente nas aulas, há deficiências que fazem com que nós, docentes, fiquemos de "mãos atadas". Afinal, essas dificuldades não começaram na pandemia, elas vêm, isto sim, da falta de estrutura e de um programa de inclusão digital e social que é negado a uma parcela significativa da população brasileira. $\mathrm{O}$ que acontece é que existem grandes disparidades entre ricos e pobres, jovens e adultos, brancos e negros e diante de uma pandemia os problemas ficam mais evidentes. Segundo aponta Demo:

Os alunos mais pobres ficarão fora, naturalmente, até porque ainda é impensável ter computador em casa e, muitas vezes, na escola. Ficar fora, entretanto, precisa ser visto dialeticamente, porque, sendo inevitável a penetração das novas tecnologias, os pobres estarão dentro, mas como excluídos. Serão 
incluídos, de qualquer maneira, na margem. Aparece, então, o desafio do que seria inclusão digital para eles. Como regra, a tendência é considerar inclusão o que não passa de efeito de poder. (DEMO, 2005, p. 38).

Nossa preocupação com o perfil desse grupo de alunos diz respeito às condições que eles possuem para absorver o conteúdo, diante de tantas dificuldades, principalmente nas disciplinas práticas. Além do estado emocional dos alunos, temos a estrutura física que o curso exige deles e eles não têm. O suporte técnico,que nem sempre o instituto tem a capacidade de fornecer, reflete-se na questão apresentada no documento disponível no Portal do MEC que assim diz: "como garantir padrões básicos de qualidade para evitar o crescimento da desigualdade educacional no Brasil?".

Apresentamos agora as especificidades dos alunos que frequentaram as aulas do Laboratório de Criação (figurino de cena) na UniRio. Vale salientar que as aulas ministradas para esse grupo são parte de pesquisa de doutorado que se encontra em andamento. Além disso, os alunos têm algumas características que achamos válido compartilhar aqui. Por se tratar de um laboratório de criação para vestuário cênico da personagem negra, a disciplina é de caráter optativa - diferentemente dos dois primeiros casos cujas cadeiras são obrigatórias - e treze dos dezessete alunos são negros. Destacamos essa característica porque, em questionário aberto à comunidade acadêmica em pesquisas que antecederam as aulas virtuais, a maior vulnerabilidade foi observada entre os alunos negros. De acordo com o Instituto Brasileiro de Geografia e Estatística (IBGE), como informa o site da Agência Brasil (2016), três em cada quatro pessoas negras fazem parte dos grupos populacionais mais pobres.

As aulas foram ministradas virtualmente no período matutino e a retomada das aulas na UniRio, mesmo virtualmente, só aconteceu em outubro. Após um longo período de afastamento da sala de aula, docentes e discentes se reencontram em um cenário ainda muito instável. Uma particularidade desse grupo é que muitos alunos já estão inseridos no mercado de trabalho e dependem diretamente de renda, cachês e verbas que, antes da pandemia, eram gerados pelo setor cultural. Esse foi um dos agravantes desse grupo, já que muitos alunos não tinham mais fonte de renda e os editais demoraram a sair. Os relatos que chegavam, por meio das justificativas de ausências nas aulas, eram as seguintes de que "surgiu um freela e eu preciso pegar" ou, "professora, eu só vou ouvir as aulas, mas não participarei das atividades porque estarei trabalhando nesse horário", ou ainda, "terei que fazer somente aulas assíncronas, você poderia gravar as aulas?". Dos dezesseis alunos, seis tiveram dificuldades em frequentar as aulas com assiduidade; um aluno assistiu somente duas aulas síncronas e todos eles faltaram, em algum momento, por motivo de trabalho. Todos são alunos negros.

Apesar das dificuldades orçamentárias, a Pró-Reitoria de Assuntos Estudantis (PRAE-UniRio) distribuiu dispositivos eletrônicos e chips $4 \mathrm{G}$ para que alunos de baixa renda pudessem acompanhar as aulas virtualmente. Devido à instabilidade das redes, contudo, falhas na conexão ocorriam com frequência, o que era apenas mais um dos problemas. Nossa reflexão está, contudo,em "quem é o responsável" quando os alunos, principalmente negros, que esperavam tanto tempo por aulas de temáticas negras, não conseguem acompanhar as aulas porque a prioridade é prover o seu sustento - ou da sua família. A crise que atinge o setor educacional é, em última instância, também cultural e não se sabe quanto tempo vai durar ou quem são os mais afetados com essa crise, agravada pela pandemia.

Como afirma Boaventura de Sousa Santos "o mundo tem vivido em permanente estado de crise", contudo "[...] a crise é, por natureza, excepcional e passageira, e constitui a oportunidade para ser superada e dar origem a um melhor estado de coisas" (SANTOS, 2020 , p. 05). Buscamos caminhos e respostas para melhorar, num futuro próximo, o estado das coisas. 


\section{Considerações finais}

Diante dos casos expostos, percebemos que a democratização do ensino não tem funcionado em sua totalidade, especialmente durante a pandemia, quando percebemos a fragilidade do ensino e como alunos e professores estão sendo prejudicados. O conteúdo ministrado no ambiente virtual não é tão eficaz quanto no presencial e o cansaço existe de ambos os lados.

Cabe lembrar que a disponibilização de dispositivos eletrônicos não é, isoladamente, suficiente para democratizar o ensino. É necessário ir além e fornecer treinamentos de qualidade para alunos e professores. Ademais, precisamos avançar na inclusão, social e digital, que possa ajudar o desenvolvimento do aluno. Enquanto professores, devemos ressaltar todas essas necessidades e, acima de tudo, buscar a valorização da nossa prática.

Para isso, é fundamental, durante o período o qual estamos vivendo, definir as prioridades educacionais embasadas na realidade do momento, tanto dos alunos quanto dos professores. É preciso ampliar o acesso e garantir o ensino para os grupos da sociedade que foram excluídos dessas ações e que continuam nas margens.

A aprendizagem é uma ação social, visto que estamos o tempo todo aprendendo algo novo e transformando conhecimentos que adquiridos previamente. Espera-se que a crise na educação, que ficou mais evidente na pandemia, seja um dos nossos maiores aprendizados dos últimos tempos. É preciso olhar para tudo que foi construído até aqui, positivamente ou negativamente, para garantir transformação, equidade, inclusão e qualidade.

Embora não saibamos mensurar todos os prejuízos, nem lançar luz sobre esse problema, de acordo com Santos (2020, p. 10) "o que a pandemia nos permitir ver e o modo como pode ser interpretada e avaliada, determinará o futuro da civilização em que vivemos. Estas aparições, ao contrário de outras, são reais e vieram para ficar". Referências Referências
AGÊNCIA BRASIL. IBGE: negros são $17 \%$ dos mais ricos e três quartos da população mais pobre. Por Isabela Vieira. Edição: Lidia Neves. 02 de dezembro de 2016.Disponível em: https://agenciabrasil.ebc.com.br/geral/noticia/2016-12/ibge-negros-sao-17-dos-mais-ricos-e-tres-quartos-da-populacao-mais-pobre. Acesso em: 30 nov. 2020.

DEMO, Pedro. Inclusão Social - cada vez mais no centro da inclusão social, Brasília, v. 1, n. 1, p. 36-38, out./mar., 2005.

MINISTÉRIO DA EDUCAÇÃO. CNE aprova diretrizes para escolas durante a pandemia. Por Bianca Estrella e Larissa Lima. 28 de abril de 2020. Disponível em: http://portal.mec.gov.br/ultimas-noticias /12-acoes-programas-e-projetos-637152388/89051-cne-aprova-diretrizes-para-escolas-durante-a-pandemia.

SANTOS, Boaventura de Sousa. A Difícil Democracia. Reinventar as Esquerdas. São Paulo: Boitempo, 2016.

SANTOS, Boaventura de Sousa. A cruel pedagogia do vírus. Coimbra: Edições Almedina, 2020.

Recebido: 10/01/2021

Aceito: 23/03/2021

Aprovado para publicação: 28/05/2021 
Este é um artigo de acesso aberto distribuído sob os termos de uma Licença Creative Commons Atribuição 4.0 Internacional. Disponível em: <http://creativecommons.org/licenses/by/4.0>.

This is an open-access article distributed under the terms of the Creative Commons Attribution License 4.0 International. Available at: $<$ http://creativecommons.org/licenses/by/4.0>.

Ce texte en libre accès est placé sous licence Creative Commons Attribution 4.0 International. Disponible sur: <http://creativecommons.org/licenses/by/4.0>. 